\title{
Erratum to: Application of simple biological analyses to screen irradiated brown rice, soybean and sesame seeds
}

\author{
Jae-Jun Ahn • Hafiz Muhammad Shahbaz • \\ Ki-Hwan Park · Joong-Ho Kwon
}

Published online: 18 March 2015

(c) The Korean Society for Applied Biological Chemistry 2015

Erratum to: J Korean Soc Appl Biol Chem (2014) 57(2),

\section{3-258}

DOI 10.1007/s13765-013-4001-0

In the second line of the Abtract in page 254, the word, "Iter" should be replaced as "filter."

The online version of the original article can be found under doi:10.1007/s13765-013-4001-0.

J.-J. Ahn · H. M. Shahbaz · J.-H. Kwon ( $₫)$

School of Food Science \& Biotechnology, Kyungpook National

University, Daegu 702-701, Republic of Korea

e-mail: jhkwon@knu.ac.kr

\section{K.-H. Park}

School of Food Science \& Technology \& Research Group on

Food Safety Control against Climate Change, Chung-Ang

University, Ansung 456-756, Republic of Korea 